\title{
Una Nueva Especie y Combinación en Wissadula (Malvaceae)
}

\author{
Massimo G. Bovini \\ Instituto de Pesquisas Jardim Botânico do Rio de Janeiro, Rua Pacheco Leão 915, 22460-030, \\ Rio de Janeiro, RJ, Brasil. mbovini@jbrj.gov.br
}

Resumen. Se presenta una nueva especie y combinación de Malvaceae, Wissadula stipulata Bovini y $W$. cuspidata (R. E. Fries) Bovini, respectivamente. Ambas fueron encontradas en el centro-oeste de Brasil, en las regiones del Pantanal y Amazónica. Se presenta la descripción e ilustración de la nueva especie, y una clave taxonómica para las especies de Wissadula en Brasil que están relacionadas. El nombre W. cuspidata es lectotipificado.

Abstract. A new species and combination in Malvaceae, Wissadula stipulata Bovini and $W$. cuspidata (R. E. Fries) Bovini, respectively, are presented. Both were found in the central-west of Brazil, in the lowlands and Amazon rainforest regions. A description and illustration of the new species are provided, and a taxonomic key of species related to Wissadula in Brazil is presented. The name $W$. cuspidata is lectotypified.

Key words: Brazil, IUCN Red List, Malvaceae, Mato Grosso do Sul, Wissadula.

El género Wissadula Medikus, posee aproximadamente 26 especies (Fryxell, 1997), ocurre básicamente en los neotrópicos, y es reconocido entre las Malvaceae, por poseer un tubo estaminal extremamente reducido y principalmente por el fruto esquizocarpo con mericarpos que presentan una constricción en la región medial, aparentando internamente, una división en dos cavidades de sus mericarpos.

La monografía de Fries (1908) fue la última obra completa para el género. Actualmente, al prepararse una revisión de Wissadula para el Brasil, se identificó una nueva especie, y se necesitó establecer una nueva combinación.

Wissadula stipulata Bovini, sp. nov. TIPO: Brasil. Mato Grosso do Sul: Bonito, Projeto Guaicurus, arredores, 14 mar. 2003 (fl., fr.), G. Hatschbach, M. Hatschbach \& E. Barbosa 74690 (holotipo, MBM; isotipo, CTES). Figura 1.

Haec species inter congeneros brasilienses Wissadulae cuspidatae (R. E. Fries) Bovini et W. excelsiori (Cavanilles) C. Presl maxime accedens, sed ab eis stipulis ca. $1.5 \mathrm{~cm}$ latis apice longe acuminatis, lamina foliari in sicco manifeste discolori, corolla ca. $1.8 \mathrm{~cm}$ diam., mericarpiis 4 atque semine in quoque mericarpio solitario distinguitur.

Arbusto erecto con $1-2.5 \mathrm{~m}$ de altura; ramas jóvenes pubérulas, blanquecinas, brilloso-sedosas, tricomas diminutos glandulares y raramente estrellados. Estípulas lanceoladas, ca. $1.5 \mathrm{~cm}$, ápice largo acuminado, base atenuada y ancha, en pares, persistentes, cara adaxial pubescente, diminutos tricomas simples, cara abaxial pubescente, tricomas estrellados. Hojas simples, enteras, membranáceas a cartáceas; lámina ovada a lanceolada, 4.5-12 × 2.5$6 \mathrm{~cm}$, ápice acuminado a agudo, base cordiforme, con lóbulos hasta $1.2 \mathrm{~cm}$, margen entera, revoluta, ligeramente ciliada, tricomas simples; nervaduras prominentes en el envés; haz marrón oscuro, glabrescente, raros e inconspícuos tricomas glandulares, envés albo-argénteo (cuando secas), tomentoso, tricomas estrellados; pecíolo $0.5-6.5 \mathrm{~cm}$, indumento y tricomas iguales a los de las ramas. Panícula ca. $30 \mathrm{~cm}$, con ramas botriomorfas, laxa; pedicelo hasta $2 \mathrm{~cm}$, antopodio hasta $1 \mathrm{~cm}$, indumento y tricomas iguales a los de las ramas; cáliz campanulado ca. $5 \mathrm{~mm}$, no engrosado en la fructificación, 5 lóbulos ligeramente cuspidados, partidos hasta la porción medial, externamente pubérulo, tricomas estrellados, internamente ligeramente pubérulo, tricomas simples largos, margen densamente vilosa, tricomas simples largos; corola alba a crema, ca. $1.8 \mathrm{~cm}$ diám., pétalo espatulado, en la margen con tricomas estrellado-estipitados en la base; filamentos concrescentes formando un tubo estaminal ca. $1 \mathrm{~mm}$, con raros tricomas estrellados estipitados y ca. $5 \mathrm{~mm}$ de filamentos libres; anteras amarillas, ca. $1 \mathrm{~mm}$; ovario glabro, 3 óvulos por lóculo; estilo ca. $6 \mathrm{~mm}$, igual al número de mericarpos, estigma capitado. Esquizocarpo ca. $8 \mathrm{~mm}$ diám., con 4 mericarpos, ca. $7 \mathrm{~mm}$ de altura, siendo menos de $1 \mathrm{~mm}$ de arista, constricción casi imperceptible, glabro, brilloso (cuando seco); 1 semilla ca. $2 \mathrm{~mm}$ de altura, vilosas en la región del hilo, tricomas largos.

Distribución y fenología. Wissadula stipulata, hasta el presente momento, se restringe al Estado de Mato Grosso do Sul, en la región del Pantanal. En el material examinado, florece y fructifica en el mes de marzo. 


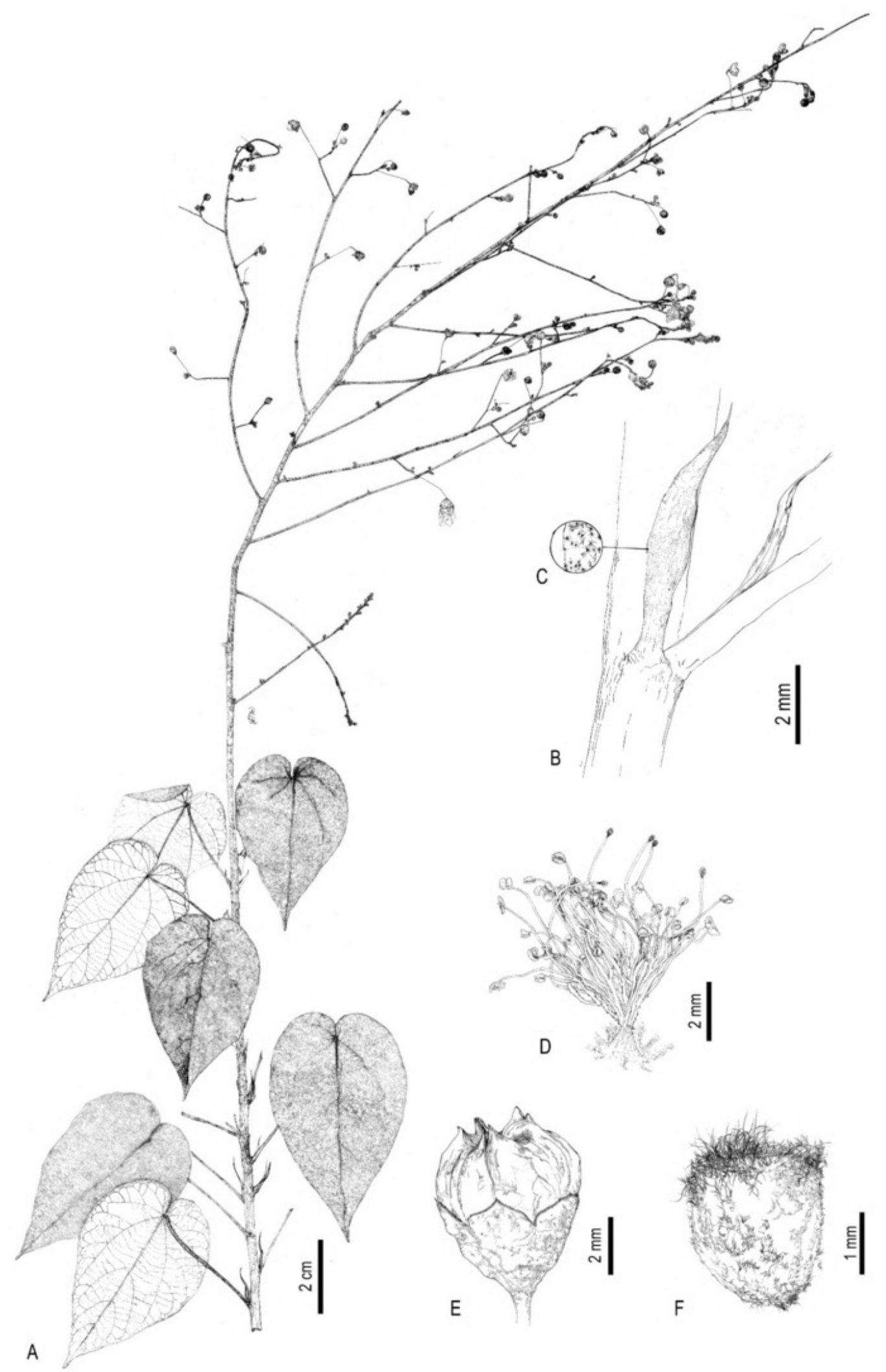

Figura 1. Wissadula stipulata Bovini. - A. Rama con flores y frutos. - B. Estípula. —C. Detalle del indumento de la estípula. -D. Gineceo y androceo. -E. Fruto. -F. Semilla. (G. Hatschbach 74690, holotipo, MBM.)

Estado de conservación. Hasta el momento Wissadula stipulata se encuentra en "Not Evaluated" (NE) de acuerdo con la IUCN (2001). No se cuenta con un estudio y colecciones suficientes de la especie, y sólo se conoce de áreas perturbadas en el mismo municipio.

Etimología. El epíteto se refiere al tamaño prominente de las estípulas. 
Discusión. Las características sobresalientes para la especie son las láminas en la región adaxial glabrescentes, tricomas glandulares raros e inconspicuos y en la región abaxial albo-argénteas, y cuando secas, se tornan más evidentes, estípulas ca $1.5 \mathrm{~cm}$ de largo, tal vez la mayor observada para el género hasta el momento y esquizocarpo con cuatro mericarpos, glabros, con una semilla en cada mericarpo. Se asemeja a Wissadula excelsior (Cavanilles) C. Presl, pero el indumento de la hoja (híspido) y del fruto (tomentoso), la forma de la base de la hoja (truncada a ligeramente cordada), la estípula menor y el número de semillas (tres) por mericarpo, las tornan distintas.

La característica, una semilla por mericarpo es diagnóstica para la sección Wissada, siendo conocidas hasta ahora dos especies: Wissadula divergens (Bentham) Bentham \& Hooker f. (Ecuador) y W. fadyenii R. E. Fries (Caribe). En W. stipulata probablemente existe un aborto de los dos óvulos colaterales, presentando sólo el desarrollo de la semilla basal. Con base en esta característica de una semilla por mericarpo, W. stipulata se considera la tercera especie de la sección Wissada.

Paratipo. BRASIL. Mato Grosso do Sul: Bonito, rod. Bonito Anastácio, 19 mar. 2004 (fl., fr.), G. Hatschbach, M. Hatschbach \& E. Barbosa 77251 (MBM).

Wissadula cuspidata (R. E. Fries) Bovini, comb. et stat. nov. Basónimo: Wissadula patens (A. SaintHilaire) Garcke subsp. cuspidata R. E. Fries, Kongl. Svenska Vetensk. Handl. 43(4): 43. 1908. TIPO: Brasil. Mato Grosso: Santa Anna da Chapada, 28 jun. 1902 (fl., fr.), A. Robert 341 (lectotipo, aquí designado, BM).

Fries (1908) analizó algunos ejemplares (Malme II s.n., BM 888516; Robert 341, BM; y Pilger 658, B [destruido] y comentó sobre las evidentes diferencias morfológicas y geográficas de éstos en relación a Wissadula patens, como hojas con pecíolos más largos, base de la lámina foliar redondeada, ápice cuspidado y con el envés más claro, estableciendo la subespecie cuspidata. Además del estudio de estos ejemplares de herbario, fue encontrado otro ejemplar colectado posteriormente en la misma área de ocurrencia, que luego de un minucioso estudio permitió elevarla a nivel de especie.

Como características diagnósticas, Wissadula cuspidata posee hojas con haz glabro, ápice agudo a cuspidado y base atenuada, además de presentar una corola menor que la especie mas relacionada, $W$. excelsior.

Material examinado. BRASIL. Mato Grosso: Aripuanã, Dardanelos, estrada Sta. Elena, 15 jun. 1974 (fl., fr.), M. $R$. Cordeiro 69 (CTES, IAN); Santa Anna da Chapada, 13 jun. 1903 (?) (fl., fr.), Malme II s.n. (BM 888516).

\section{Clave Para el Reconocimiento de las Especies de Wissadula} Relacionadas En BrasiL

la. Estípulas ca. $1.5 \mathrm{~cm}$ largo, ápice largo acuminado; lámina foliar nítidamente discolor (cuando seca); corola ca. $1.8 \mathrm{~cm}$ de diám.; una semilla por mericarpo. . . . . . . . . . . . . stipulata

1b. Estípulas ca. $1 \mathrm{~cm}$ de largo, ápice agudo; lámina foliar levemente discolor; corola ca. $1 \mathrm{~cm}$ de diám. o menos; tres semillas por mericarpo . . . . . . . 2

2a. Haz de la lámina foliar glabra; base atenuada; corola ca. $0.9 \mathrm{~cm}$ de diám.........W. cuspidata

2b. Haz de la lámina foliar híspida; base truncada a ligeramente cordada; corola ca. $1.1 \mathrm{~cm}$ de diám. ..

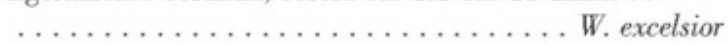

Agradecimientos. A los profesores Giovani R. Milla y Mauricio S. Yepes, por la traducción del artículo al español, a la ilustradora Rachel Rosadas por la confección de la lámina y a Tarciso Filgueiras por la diagnosis en latín.

\section{Literatura Citada}

Fries, R. E. 1908. Entwurf einer Monographie der Gattungen Wissadula und Pseudabutilon. Kongl. Svenska Vetensk. Handl. 43(4): 1-114.

Fryxell, P. A. 1997. The American genera of Malvaceae II. Brittonia 49(2): 261-262.

IUCN. 2001. IUCN Red List Categories and Criteria, Version 3.1. Prepared by the IUCN Species Survival Commission. IUCN, Gland, Switzerland, and Cambridge, United Kingdom. 


\section{$2 \mathrm{BHL}$ Biodiversity Heritage Library}

Bovini, Massimo G. 2009. "Una Nueva Especie y Combinación en Wissadula (malvaceae)." Novon a journal of botanical nomenclature from the Missouri Botanical Garden 19, 15-17.

View This Item Online: https://www.biodiversitylibrary.org/item/124658

Permalink: https://www.biodiversitylibrary.org/partpdf/121868

\section{Holding Institution}

Missouri Botanical Garden, Peter H. Raven Library

\section{Sponsored by}

Missouri Botanical Garden

\section{Copyright \& Reuse}

Copyright Status: Permission to digitize granted by rights holder Rights: https://www.biodiversitylibrary.org/permissions

This document was created from content at the Biodiversity Heritage Library, the world's largest open access digital library for biodiversity literature and archives. Visit BHL at https://www.biodiversitylibrary.org. 